\title{
Interview
}

\section{An interview with Thomas Morton on CLIL methodology in Spain}

\author{
Alicia Fernández Barrera \\ University of Castilla-La Mancha
}

(Text received July 14 2017; accepted July 17 2017)

DOI: http://doi.org/ 10.5565/rev/jt13.763

\begin{abstract}
Tom Morton is an honorary research fellow in the Department of Applied Linguistics and Communication, Birkbeck, University of London. His research interests include teacher knowledge and identity, classroom interaction and language development in TESOL and Content and Language Integrated Learning (CLIL). He is a member of the UAM-CLIL research group based at the Universidad Autónoma de Madrid, with which he has participated in several national and international CLIL research projects. He is co-author of two books on CLIL: The Roles of Language in CLIL, with Ana Llinares and Rachel Whittaker, published by Cambridge University Press in 2012, and Applied Linguistics Perspectives on CLIL, with Ana Llinares, published in 2017 by John Benjamins. This book was awarded the AESLA Senior Investigator prize. His most recent book is Social Interaction and English Language Teacher Identity, with John Gray, and published by Edinburgh University Press (2018). He has published numerous articles in leading journals and book chapters on TESOL and CLIL, and is co-founder of the journal Classroom Discourse.
\end{abstract}

\section{Interview (June 2017)}

Interviewer: Dr. Morton, your recent research has focused on Content and Language Integrated Learning (CLIL), in which academic content is taught through the medium of an additional (foreign, second) language. What is your opinion about CLIL research in Spain?

Morton: My opinion about CLIL research in Spain? Basically, I think it is quite healthy. In terms of quantity, there's a lot, and when I speak to CLIL researchers or bilingual education researchers in other parts of the world, they always say that Spain is kind of like a centre for CLIL practice and CLIL research because, for better or worse, it's being seen as a policy initiative in Spain, so the regional governments are putting 
quite a lot of investment into bilingual education and that, in turn, attracts research. So, we have colleagues, I know quite a few people who work in Andalucía on CLIL research in Pablo de Olavide University, or people who work in the Basque country or Cataluña, of course the people I work with in Madrid... So, I would say healthy. It doesn't mean there aren't any problems and these might come up with other questions but the answer to that question is very active and healthy.

Interviewer: And what is your opinion about CLIL as a type of bilingual education programme? You know here in Spain we call this kind of bilingual education programmes 'bilingual programmes'. So, what's your opinion? Do you think that is a good label to define bilingual programmes in this monolingual community [Castilla-La Mancha]?

Morton: So, you are referring to communities like here, like Castilla-La Mancha? Whether we can use the term CLIL here as opposed to using it in a bilingual community such as the Basque country or... I don't think it really matters that much whether the use or non-use of the term CLIL really is connected with whether the area or the context is monolingual or bilingual. There are other issues around the use of the term CLIL, about whether CLIL is best used to refer to a kind of a set of methodological principles for integrating content and language, or whether it is an adequate label to describe programmes. That's why I am not so sure whether it is always clear to use the term CLIL to distinguish programmes. So, we have like immersion programmes in different countries, in Canada and Europe; we have them in the UK, in Wales and Ireland; then, we have content-based language instruction, English medium instruction. Some people would - I think - would like to use CLIL to distinguish the kind of European context where a foreign language such as English is used as a medium of instruction. But, then again, it does not always work because, in fact, there are some schools and some teachers who are teaching English, teaching content through another language, and perhaps they haven't heard of the term CLIL before. They haven't heard of it. I do teacher training and I go to - less now -, but when I first started 10 years ago, I would go to a school or teacher training centres, including in Castilla-La Mancha, Cuenca or Guadalajara, for example, and I would start talking about CLIL, and I realised that for my next session I should explain what CLIL is on the first day, because it was known as 'bilingüismo' or 'bilingual education'. 
Interviewer: Yeah, because here in our context in Castilla-La Mancha it seems that teachers that are involved in these bilingual programmes are not really very aware of their own CLIL practices, so that's why it is a controversial issue to label this kind of bilingual education programmes as 'CLIL' programmes.

Morton: Yeah, because, you know... And seen from a different perspective, you could say if CLIL is as it is described by Do Coyle and David Marsh, and others who work in Spain like Phil Ball, if it is a set of methodological procedures, if teachers aren't using that methodology, then it is difficult to call it 'CLIL', because, at the very least, to call something 'CLIL', according to those definitions, you need to have some attention to language objectives along with the content objectives. In many bilingual schools, English is used as a medium of instruction but it's not really a focus of attention itself as language, so you could argue then that, perhaps, they are not doing CLIL, they are doing something more like EMI. They are using English as a medium of instruction

Interviewer: And what do you think are the main challenges in the current implementation of CLIL (organization, school management, classroom practices, curricula)? What is your opinion?

Morton: Policy and school management are not my areas of research, so I am usually reluctant to say much about those areas. But I have heard this morning quite a lot about collaboration and how schools are managed, then it is very important, it is almost like a specialised area. Concerning what I know about more, I would say, two areas of concern would be - I think - the biggest one is teacher education and professional development, and not just about teachers' language skills or language proficiency... about teachers' knowledge about teaching and knowledge about how to integrate content and language. I think that is really important. Some efforts have been made to provide teachers with adequate training but it's never going to be enough. And there needs to be more programmes, there needs to be more master's level programmes and sustained programmes so teachers have long teaching practice and they have exposure to a range of options, methodological options for integrating content and language. And the other thing that may be lacking may be clearer principles for the integration of content and language than those that already exist. I think there's some confusion at 
times that content is mixed with aspects of language which may not have much to do with content, so, if teachers are teaching content and, then, they are only correcting a few mistakes, it is not really integrating content and the language. So, I think those two things go together: clearer, more - perhaps - theoretically based principles for the integration of content and language, which are then translated into methodological options. And materials even, and then, which teachers have the chance to learn how to use through professional development. So, I would say those are the key areas.

Interviewer: My next question is what is your experience working with CLIL teachers? How could we bring together CLIL teachers and researchers?

Morton: I think that's another problematic area. I think it's, in general, too much research is research on teachers and not research with teachers. So, we are researching them, or researching on them. Sometimes, we try to bring them in and, at the current project I am working with at the Autónoma [Universidad Autónoma de Madrid], we are developing tasks for the students to do with their teachers, so teachers are involved in developing the tasks that with the students they then do, and then we analyse their linguistic productions. But that's not really all. We could go a lot further. I would really like to see types of teacher development and teacher research such as lesson study, which is used in Japan and more and more in Europe and the States, in which teachers are researchers; they are researching their own practice and they may work with a university researcher. But they are producing knowledge; they are not just willing participants in our research projects. So, I think that's a real... I haven't really found the answer to that because I haven't really... A couple of teachers I know, there's one at the Autónoma, who was, when I was collecting data at the beginning, she is now doing her $\mathrm{PhD}$ with us, that's a teacher becoming a researcher, but that's quite a rare case. So, we need to do it, and especially with content teachers, especially with teachers who are not language teachers, we need to find the ways in which we can work with them, to develop units, to develop lessons in which they become producers of knowledge along with us, rather than being just subjects of our research.

Interviewer: In your current work (with John Gray of the Institute of Education) you focus on different language teacher identities emerging in and through social interaction 
in a range of contexts. Could you tell us about your research on teachers' social interaction and the relationship between discursive practices and identity construction?

Morton: Ok. Well, this is going to be a book which will come out in a few months, hopefully, we are just finishing it. What we are trying to do in this book is... We know that teacher identity has become quite a hot topic at the moment. It's coming... The focus that was dominant a few years ago on teachers' beliefs and teachers' knowledge, teacher cognition in general, has been... Recently, identity has kind of taken over a little bit, it's been kind of one of the key ways to look at teachers and to understand what teachers do, and, obviously, who they are, who they see themselves as being, and there have been quite a lot of recent publications on teachers' identity in many contexts. What we are trying to do is look at how identities are produced or emerge through discursive actions. So, we are trying to add something to that literature which perhaps is an angle that has not been explored so much. It's been explored in other areas of looking at language and society, looking at the discursive production of identity. I am thinking of work by Elizabeth Stokoe and Bethan Benwell on discourse and identity over 10 years ago. So, there is a lot of work on identity and discourse but maybe not so much on teacher identity as it is produced in the moment during interaction in as far as possible naturally-occurring contexts. But, also, in this book, we consider research interviews or focus groups to be naturally-occurring contexts as well, just as natural as teaching in the classroom. We are still looking at the big issues of identity, we are looking at expert and novice identities, we are looking at something that has not been done so much in applied linguistics, social class, identity, political identity, which has been looked at by David Block, of course. We are looking at LGBT identity, teachers' LGBT, or queer identity. So, these things have been looked at in the literature, but perhaps not so much through the details of the unfolding interactions that the teachers and the other, sometimes the other teachers... sometimes there might be an interview or researcher, and we think we can perhaps shed some light on these issues by looking at the way identities are produced in discourse.

Interviewer: And regarding teachers' identity construction, what is the role of languages? Is there any particular language you are looking at? 
Morton: It's English because the title of the book is Social Interaction and ELT Teacher Identity. We were originally thinking about just having language teaching, but then, as a practical matter, most of our data comes from English language teachers, and there are some issues. There is one chapter in the book which looks at English as a lingua franca or international language, and how teachers see themselves in terms of their identity. So, we thought it would give the book a clearer focus if we just linked it to English language teacher identity in order not to try to cover too much all language teacher identity. But the language is English, basically.

Interviewer: Part of your research is focused on spoken interaction in classroom settings, what are the benefits of such analysis?

Morton: I think the benefits of this analysis are twofold: you can talk about benefits from the point of view of researchers who are interested in the nature of human interaction, social interaction, learning, psychological development, all these things... If you have a very close-up analysis of how people use different modes of communication in order to achieve their goals, learning goals in classroom situations, you might be able to uncover some surprising things they are doing that perhaps you didn't expect. So, if you kind of set aside your theories for a moment and you look close-up at the interactional data, you might discover from the participants' perspective that they are doing things and perhaps they were more competent than you imagined them to be before you looked at what they are actually doing. So, I think there's a lot we can learn about the processes of human interaction or human sociality, as it is sometimes called, just from the point of view of knowledge, knowing how human beings accomplish the things they want to do in face-to-face interaction. And, if it's learning, if learning is the goal, how learning is organised as a participants' matter.

The second benefit is, perhaps not in such great detail or such rigour, but teachers can be offered tools which allow them to record their own interactions in the classroom and they may be able to have tools to classify what they do or to reflect on what they do. For example, teachers can use a simple tablet or mobile phone to record their teaching, and there are some programmes which allow them quite quickly to categorise events. And then, they can sit down with themselves, or researchers, or other teachers, and use these as tools for reflection. So, reflection becomes not just something that happens in a vacuum, you know, you write an essay about your teaching, you have 
some data that you can use for reflection. So, it can be a real aid to helping teachers to reflect on their practice.

Interviewer: So, as feedback for teachers, I mean, for them to reflect upon their own practices.

Morton: Yeah, some people are writing about this and calling it 'data-driven reflection'. So, you have some evidence of what you did, and video evidence is quite immediate. Of course, it can be transcribed if you want to transcribe it and look at it in more detail, but even without transcribing it, you can still code a lesson into different stages or events and use this as a basis for reflection.

Interviewer: My last question is more a reflection upon CLIL research in Spain. So, CLIL research has dramatically developed in Europe and Spain, from your point of view, what is still missing and what are the main challenges? Is there something missing in CLIL research?

Morton: I think not so much is missing but things are moving. I am thinking about the work done by what's called the Graz Group. You know, people like Do Coyle, Oliver Meyer and Ana Halbach in Alcalá, which is looking at pluriliteracies. It is looking at... They started looking at combining content and language, you know, combining a subject such as Geography with a foreign language such as English, but looking at the role of language across the curriculum and the role of language in all learning. And that's one of the things that myself and other CLIL researchers have discovered: that doing CLIL or researching CLIL raises lots of questions about the nature of language and literacy in all learning, not just for language learning and specific content subjects. So, I think CLIL... What has been missing, perhaps, and I think the work we've been doing with Ana Llinares and Rachel Whittaker at the Autónoma has contributed to filling this gap. It's looking at the subject specific literacies that students are learning and, then, moving this beyond individual subjects to literacy across the curriculum. I think that's maybe... there has been a gap but it's starting to be filled and it may be where CLIL is going in the future, and may be breaking out of the kind of foreign language teaching and specific subjects but raising really deep questions and important 
questions about the role of language in all learning, even in the so-called native language. So, I think that's been missing.

I think a big thing that is still missing, there is a lack of involvement of content specialists in CLIL, by that I mean primary and secondary, and even tertiary teachers of content, and also content researchers. I'm talking about Mathematics educators or Science educators. I don't think there's enough dialogue between content specialists, whether they are teachers or researchers, and applied linguists, who have basically been dominant - I suppose - in CLIL research. I'm not sure there are too many signs of that changing but it does need to change. We need to bring in, especially, people in the content areas who are interested in language and discourse. And those people exist. I used to work in a School of Education (University of Leeds) and I worked with a Science educator, so they were very interested in discourse, but they had not heard of CLIL. So, there's lots of potential to work together. And I think, also, what's missing in CLIL, the more it has a language teaching background, it fails to engage with the way knowledge is organised in specific subjects. That's another thing we need to look at. The way knowledge is structured or organised in different subjects and the implications for focusing on language. It may not be the same. We may not have the same approach to language and Mathematics as we have in Science, or History, or Philosophy, depending on the structure of knowledge in those subjects.

Interviewer: Thank you very much.

\section{References}

Ball, P., Kelly, K., \& Clegg, J. (2016). Oxford handbooks for language teachers: Putting CLIL into practice. Oxford: Oxford University Press.

Benwell, B., \& Stokoe, E. (2006). Discourse and identity. Edinburg: Edinburgh University Press.

Block, D. (2009). Second language identities. London: Bloomsbury Publishing.

Block, D. (2006). Multilingual identities in a global city: London stories. London: Routledge.

Coyle, D., Hood, P., \& Marsh, D. (2010). Content and language integrated learning. Cambridge: Ernst Klett Sprachen. 
Coyle, D. (2007). Content and language integrated learning: Towards a connected research agenda for CLIL pedagogies. International Journal of Bilingual Education and Bilingualism, 10(5), 543-562. DOI: https://doi.org/10.2167/beb459.0

Coyle, D. (2006). Developing CLIL: Towards a theory of practice. Monograph 6. Barcelona: APAC Barcelona.

Gray, J. \& Morton, T., (Eds.) (Forthcoming). Social interaction and ELT teacher identity. Edinburgh: Edinburgh University Press.

Llinares, A., Morton, T., \& Whittaker, R. (2012). The roles of language in CLIL. Cambridge: Cambridge University Press.

Mehisto, P., Marsh, D., \& Frigols, M. J. (2008). Uncovering CLIL content and language integrated learning in bilingual and multilingual education. Oxford: Macmillan Education.

\footnotetext{
Author information

Alicia Fernández Barrera is a Research Fellow at the University of Castilla-La Mancha (UCLM), Spain, in the Department of Modern Languages, Faculty of Arts and Humanities (Ciudad Real). She researches bilingualism, language ideologies and language policies in educational CLIL contexts. She holds a Research Fellowship from the Spanish Ministry of Education, Culture and Sport (2015-2019). She has a MA in Arts and Humanities Research, a MA in Teacher Training and a BA in English Studies from the UCLM. She recently accomplished a three-month research stay at the UCL-Institute of Education under the supervision of Dr Miguel Pérez-Milans (October 4, 2016-January 3, 2017).

E-mail: $\underline{\text { Alicia.FBarrera@uclm.es }}$
}

To cite this article:

Fernández Barrera, A. (2018). An interview with Thomas Morton on CLIL methodology in Spain. Bellaterra Journal of Teaching \& Learning Language \& Literature, 11(1), 96-104. DOI: http://doi.org/ $10.5565 / \mathrm{rev} / \mathrm{jtl} 3.763$

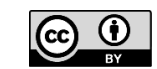

